Check for updates

Cite this: RSC Adv., 2019, 9, 20035

\title{
Fabrication of Tween-20 coated PVDF membranes for wastewater treatment: optimization of preparation parameters, removal and membrane fouling control performance $\uparrow$
}

\author{
Daoji Wu, ${ }^{a}$ Weiwei Zhou, ${ }^{\text {ab }}$ Xiaoxiang Cheng, (DD *a Congwei Luo, ${ }^{\text {*a }}$ Peijie Li, ${ }^{a}$ \\ Fengzhi Zhang ${ }^{a}$ and Zixiao Ren $^{a}$
}

\begin{abstract}
In the present study, polyoxyethylene (20) sorbitan monolaurate (Tween-20) was employed as a surface coating agent for hydrophilic modification of poly(vinylidene fluoride) microfiltration membranes. The optimized parameters for membrane preparation (i.e., coating temperature, coating concentration, coating time and drying time) were systematically investigated. Contact angle and transmembrane pressure were employed to evaluate the efficiency of the modified membranes, and the optimized parameters were proposed. The removal of chemical oxygen demand (COD) and suspended solids (SS), as well as fouling control performance, was further evaluated. The results showed that the optimized parameters were $40{ }^{\circ} \mathrm{C}, 4.5 \mathrm{mmol} \mathrm{L}{ }^{-1}, 45 \mathrm{~min}$ and $45 \mathrm{~min}$ for coating temperature, coating concentration, coating time and drying time, respectively. Under these conditions, a hydration layer on the surface was formed, resulting in a more hydrophilic membrane surface. During domestic wastewater treatment in membrane bioreactor (MBR), the Tween-20 modified membrane exhibited better performance with rejection efficiencies of $94.56 \%$ and $97.53 \%$ for COD and SS, respectively. Tween-20 coating could mitigate the increase of transmembrane pressure and reduce the concentration of proteins accumulated on the membrane surface, which was effective for membrane fouling control. Simultaneously, the operation time of MBR was extended from 25 to 46 days. Furthermore, the stability of Tween-20 coated PVDF membrane was also verified. The results indicated that surface coating with Tween-20 is efficient and easy to be carried out, showing a great potential for application in MBR during wastewater treatment.
\end{abstract}

Received 12th May 2019

Accepted 20th June 2019

DOI: $10.1039 / c 9 r a 03549 d$

rsc.li/rsc-advances
Usually, a hydration layer is easily formed on the surface of a hydrophilic membrane, which could prevent the deposition and adsorption of pollutants on the membrane surface, thereby reducing the fouling of the membrane. ${ }^{13-15}$ Poly(vinylidene fluoride) (PVDF) has been widely used to produce microfiltration and ultrafiltration membranes due to its excellent chemical resistance, thermal stability, processability and mechanical properties. ${ }^{16-19}$ However, PVDF has fairly low resin surface energy and extremely strong hydrophobicity, leading to serious adsorption fouling, as well as reduced membrane flux and service life. Consequently, increasing the resistance of pollutants adsorption and service life of membrane using the method of hydrophilic modification has become a hotspot in the field of membrane materials.

In general, hydrophilic modification of PVDF membrane includes two methods, i.e., membrane intrinsic and surface modification. The essence of membrane modification is to mix membrane material with hydrophilic polymer or inorganic nano-materials, which can bring in a hydrophilic layer to the surface of PVDF membrane and prevent its contact with
${ }^{a}$ School of Municipal and Environmental Engineering, Shandong Jianzhu University, Jinan, Shandong, China, 250101.E-mail: cxx19890823@163.com; luocongwei@ sdjzu.edu.cn

${ }^{b}$ Shandong Urban Construction Vocational College, Jinan, Shandong, China, 250103 $\dagger$ Electronic supplementary information (ESI) available. See DOI: 10.1039/c9ra03549d 
pollutants. $^{20}$ Surface modification of membrane includes surface coating and graft modification. ${ }^{21}$ With respect to the coating modification, physical reaction is used to fix hydrophilic layers to the surface of membrane, which will not change the chemical constituents of PVDF membrane and operate simply. Boributh et al. ${ }^{22}$ used $1.0 \%$ (mass fraction) chitosan and three different adding modes to modify a $0.22 \mu \mathrm{m}$ PVDF flat sheet membrane. The results showed that the pure water contact angle of modified membranes obviously decreased, indicating that the hydrophilicity of modified membranes significantly increased. Zhang et $a .^{23}$ modified PVDF membranes with tannin coating using a simple dip-coating method. The result indicated that the modified membranes exhibited prominent separation performance for emulsion and excellent antifouling property. Surface graft modification ${ }^{24}$ is another method to improve the surface hydrophilicity by grafting hydrophilic monomers or inorganic nanoparticles onto the PVDF membrane surface. In the study of Liu et al. ${ }^{25}$ surface grafting modification was performed by the following method. Firstly, PVDF membranes were pre-irradiated by electron beam in vacuum, and then the hydrophilic sulfonated groups were introduced by the single step grafting method with binary monomer solution of acrylic acid and sodium 4-styrenesulfonate. Finally, the water contact angle of the membrane surface significantly decreased, indicating the improvement of the surface hydrophilicity.

The surfactant ordinarily combines at least two kinds of functional groups which have significantly different polarity medium tendency. With the influence of functional groups, the conterminous interface will form directional selection adsorption, hence changing the state and nature of interface. Since an ionic surfactant is charged, membrane pollutants with the same charge can be excluded by electrostatic interaction, thus reducing interface absorption during water treatment. Non-ionic surfactant reduces pollutants deposition mainly through forming dense hydrophilic layers on the surface. To the best of our knowledge, it is still lack of systematic studies about the effect of coating non-ionic surfactant on the performance of PVDF microfiltration during wastewater treatment. Polyoxyethylene (20) sorbitan monolaurate (Tween-20) is one of the typical non-ionic surfactants, which was usually used as a pore forming agent in membrane preparation..$^{26,27}$ In comparison with ionic surfactants, non-ionic surfactants represented by Tween-20 are more stable in the water and less susceptible to acid and alkaline solutions, which could be much safer and cheaper for membrane hydrophilic modification. Xie et al. ${ }^{28}$ modified polypropylene membrane by adsorption of various Tween surfactants, i.e., Tween-20, Tween-40, Tween-60, Tween-80 and Tween-85. The results indicated that Tween20 exhibited certain advantages over other surfactants for decreasing contact angle, and showed much higher adsorption amount at low concentration. To this end, Tween-20 was chosen as one of the typical non-ionic surfactants for hydrophilic modification of PVDF microfiltration membrane. In comparison with blending modification, surface coating is easier to perform, which can be directly used on the surface of commercially available membranes. As far as we know, very limited work on the fabrication of Tween-20 coated PVDF microfiltration membrane has been reported, especially for the optimization of preparation parameters. This work aims at preparing hydrophilic antifouling membranes for wastewater treatment, which oriented the design of preparation parameters.

In the present study, Tween-20 was introduced to coat PVDF microfiltration membrane, and the preparation parameters (i.e., coating temperature, coating concentration, coating time and drying time) were systematically investigated and optimized. Then, the removal performance of Tween-20 coated PVDF membrane and original membrane on COD and SS during wastewater treatment were evaluated. The fouling control performance were further studied by testing the increase of transmembrane pressure and accumulation of proteins on membrane surface. Finally, the stability of modified membrane was investigated. The results were expected to demonstrate the feasibility of surface coating with Tween-20 to simultaneously improve the performance of pollutants removal and membrane fouling control.

\section{Materials and methods}

\subsection{Materials}

In this study, a PVDF hollow fiber microfiltration membrane provided by Tianjin Motimo Membrane Technology Co., Ltd was employed, and the characteristics of membrane are shown in Table S1. $\uparrow$ Tween-20 supplied by BioFroxx (Einhausen, Hessen, Germany) was used as a typical non-ionic surfactant. The chemical structural formula of Tween-20 is shown in Fig. S1. $\dagger$ The quality of raw wastewater in this study is shown in Table S2.†

\subsection{Preparation of Tween-20 coated PVDF membrane}

To prepare Tween-20 coated PVDF membrane, the virgin membrane was firstly immersed in ultrapure water for $48 \mathrm{~h}$ to remove conservation reagents and impurities on membrane surface. Then, the membrane was immersed in Tween-20 solutions with different concentrations under various coating temperatures and times, followed by drying in an oven with different drying times. Finally, the Tween-20 coated PVDF membrane was obtained. The detail parameters used to prepare the membrane are shown as follows:

(1) Coating temperature is the required temperature of drying oven, expressed as $T$. The experimental levels were $40{ }^{\circ} \mathrm{C}$, $80{ }^{\circ} \mathrm{C}$ and $120{ }^{\circ} \mathrm{C}$, respectively.

(2) Coating concentration is the loading mass of Tween-20, expressed as CC. The experimental levels were 1.8, 4.5, 9.0 and $18.0 \mathrm{mmol} \mathrm{L}^{-1}$, respectively.

(3) Coating time is the soaking duration in Tween-20 solution. The experimental levels were 10, 15, 25 and $45 \mathrm{~min}$, respectively.

(4) Drying time is the duration in the drying oven. The experimental levels were 30, 45, 90 and $120 \mathrm{~min}$, respectively. 


\subsection{Experimental setup of MBR}

The schematic diagram of the experimental setup for MBR is shown in Fig. 1, and the photo of the device is illustrated in Fig. S2. $\dagger$ As seen in Fig. 1, the experimental setup was composed of raw water tank, inlet water pipe, balance tank, bioreactor, membrane module, outlet water pipe, aeration system, and pressure measuring pipe. Raw water flowed into the balance tank from the raw water tank by gravity, and the balance tank controlled the level of the bioreactor by the float valve. Raw water entering the balance tank was evenly distributed into the bioreactor through the outlet pipe at the bottom of the tank. The bioreactor was a plexiglass column with a diameter of $0.2 \mathrm{~m}$ and an effective water depth of $0.75 \mathrm{~m}$. The bioreactor provided dissolved oxygen for microorganisms in the aeration tank by sand filter aerator and produced cross-flow fluid which scour the membrane surface. The aeration rate was controlled by gas rotor flowmeter. The height difference between the surface of the reactor and the effluent provided the driving force for the effluent water, and the effluent water quantity was adjusted by the rotor flowmeter. In order to monitor the condition of membrane fouling, a pressure meter was made according to the principle of communicator, and the liquid level of the pressure tube reflected the variation of transmembrane pressure.

\subsection{Analytical methods}

2.4.1 The measurement of contact angle. A JY-82 contact angle goniometer (range of contact angle measurement: $0-180^{\circ}$; test accuracy: 1 degree) was used to test the contact angle of membrane surface with deionized water. It was noted that contact angle reflected the invasion of water to membrane surface, and a bigger contact angle value indicated less membrane surface hydrophilicity. ${ }^{29}$ In the measurement of contact angle, five measurements at different locations of

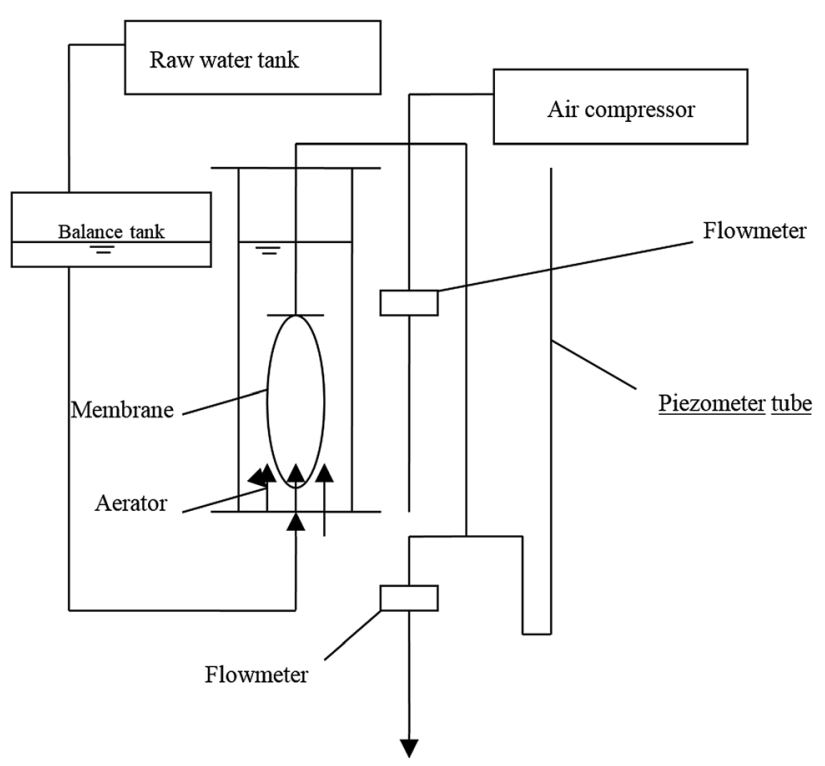

Fig. 1 Schematic diagram of MBR experimental setup for wastewater treatment. membrane surface were carried out and the average value was obtained.

2.4.2 The extracting of extracellular polymeric substances (EPS). The deposited cake layer was scraped from a certain area of membrane surface, and dissolved in $50 \mathrm{~mL}$ phosphate buffered saline with $\mathrm{pH}$ of $7.4\left(10.0 \mathrm{mmol} \mathrm{L}{ }^{-1} \mathrm{Na}_{2} \mathrm{HPO}_{4}, 2.0 \mathrm{mmol}\right.$ $\mathrm{L}^{-1} \mathrm{KH}_{2} \mathrm{PO}_{4}, 137.0 \mathrm{mmol} \mathrm{L}^{-1} \mathrm{NaCl}$, and $2.7 \mathrm{mmol} \mathrm{L}^{-1} \mathrm{KCl}$ ). Then, EPS was extracted by heating the solution at $80{ }^{\circ} \mathrm{C}$ for $30 \mathrm{~min}$, followed by ultrasound at $120 \mathrm{~W}$ for $5 \mathrm{~min}$ and centrifuging at $10000 \mathrm{~g}$ for $20 \mathrm{~min} .^{30}$ The supernatants were collected to analyze the concentration of proteins according to the method proposed by Lowry et al. ${ }^{31}$

2.4.3 Other analytical methods. The chemical oxygen demand (COD) and suspended solids (SS) were determined by using standard method..$^{32}$ All experiments were performed in duplicate, and the averages were recorded with deviations of less than $5 \%$. The surface morphologies of original and modified membranes were observed using a scanning electron microscope (SEM, JSM-7610F, JEOL, Japan). The operating conditions of the SEM instrument are shown as follows: accelerating voltage $=5.0 \mathrm{kV}$, emission current $=55 \mu \mathrm{A}$, work distance $=6.6 \mathrm{~mm}$. To prepare SEM samples, the membranes were firstly dried in a desiccator $\left(45{ }^{\circ} \mathrm{C}\right)$ for $72 \mathrm{~h}$ and fixed on a copper sheet, then coated with gold by a precision etching coating system (JEC-3000FC, JEOL, Japan). An atomic force microscopy (AFM, Bioscope, Veeco, USA) was employed to characterize the roughness of membrane surface. The functional groups of membrane surfaces were identified using an attenuated total reflectance Fourier transform infrared (ATRFTIR) spectroscope (Nicolet6700, Thermo Scientific, USA).

\section{Results and discussion}

\subsection{Optimization of preparation parameters}

3.1.1 Coating temperature. Coating temperature is an important factor influencing the preparation of Tween-20 coated PVDF membrane. The influence of coating temperature on the apparent appearance of the membrane was investigated and the surface morphologies under different coating temperatures are shown in Fig. 2. Fig. 2(a) illustrates that membrane pores could be seen clearly on the surface of the original membrane. After coating under various temperatures, the modified membranes exhibited different surface morphologies due to the presence of Tween-20 coating on membrane surfaces. To be specific, the surface of modified membrane at $40{ }^{\circ} \mathrm{C}$ was smoother and some large pores could be observed on membrane surface (Fig. 2(b)). When the coating temperature was increased to $80{ }^{\circ} \mathrm{C}$, the membrane surface became rougher and less elastic because of the reinforcement between membrane surface and non-ionic surfactant (Fig. 2(c)). As shown in Fig. 2(d), the modified membrane exhibited greatest surface roughness at $120{ }^{\circ} \mathrm{C}$ and the pores could not be seen clearly. Since the distortion temperature and melting point of PVDF materials are $112-145{ }^{\circ} \mathrm{C}$ and $172{ }^{\circ} \mathrm{C}$, respectively, the deformation of PVDF materials occurred when the temperature was higher than $112{ }^{\circ} \mathrm{C}$, resulting in a compact and rough surface morphology. Sun et al. ${ }^{19}$ modified PVDF membrane with 

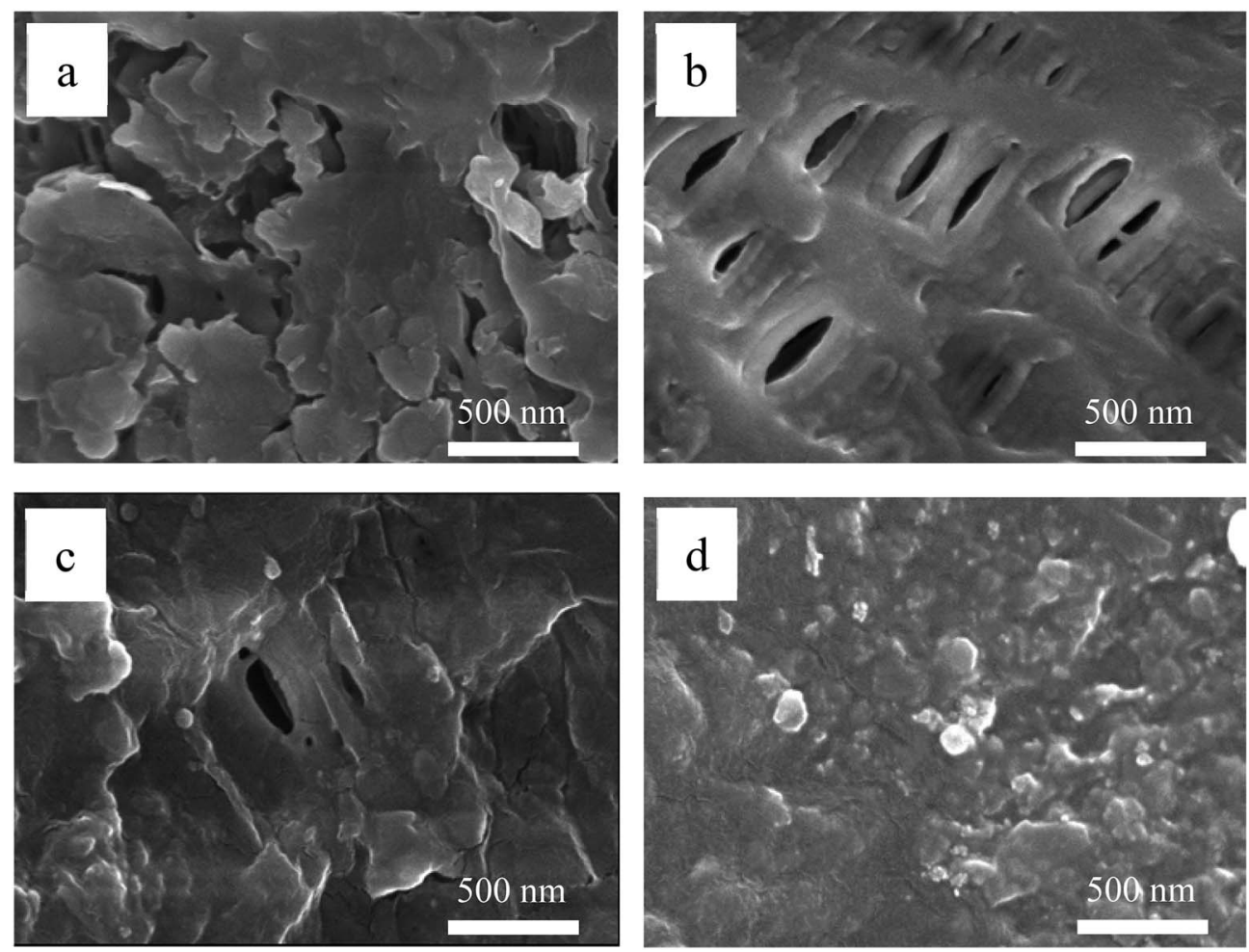

Fig. 2 SEM images of the original membrane (a) and Tween-20 coated membranes under the coating temperature of $40{ }^{\circ} \mathrm{C}$ (b), $80{ }^{\circ} \mathrm{C}$ (c) and $120^{\circ} \mathrm{C}(\mathrm{d})$.

monoethanolamine, and found that the modified membranes at a higher temperature were more hydrophilic. This was because that an increase in the temperature increased the reaction rate and more fluorine was eliminated from the polymer backbones. However, the PVDF membranes treated by monoethanolamine solutions at $80{ }^{\circ} \mathrm{C}$ for $24 \mathrm{~h}$ became very fragile.

AFM was further employed to characterize membrane surface roughness, and the results are shown in Fig. 3. The average plane roughness $\left(R_{\mathrm{a}}\right)$ value for the original membrane was $7.4 \mathrm{~nm}$. By contrast, the modified membrane prepared at $40{ }^{\circ} \mathrm{C}$ was the smoothest with $R_{\mathrm{a}}$ of $5.8 \mathrm{~nm}$, and the roughness increased with the increase of coating temperature. Under the coating temperature of $80{ }^{\circ} \mathrm{C}$ and $120{ }^{\circ} \mathrm{C}$, the $R_{\mathrm{a}}$ values were increased to 8.6 and $10.5 \mathrm{~nm}$, respectively. Note that the increased roughness was likely attributed to the deformation of PVDF material, showing a negative effect on membrane contact angle and hydrophilicity. In addition, reducing surface
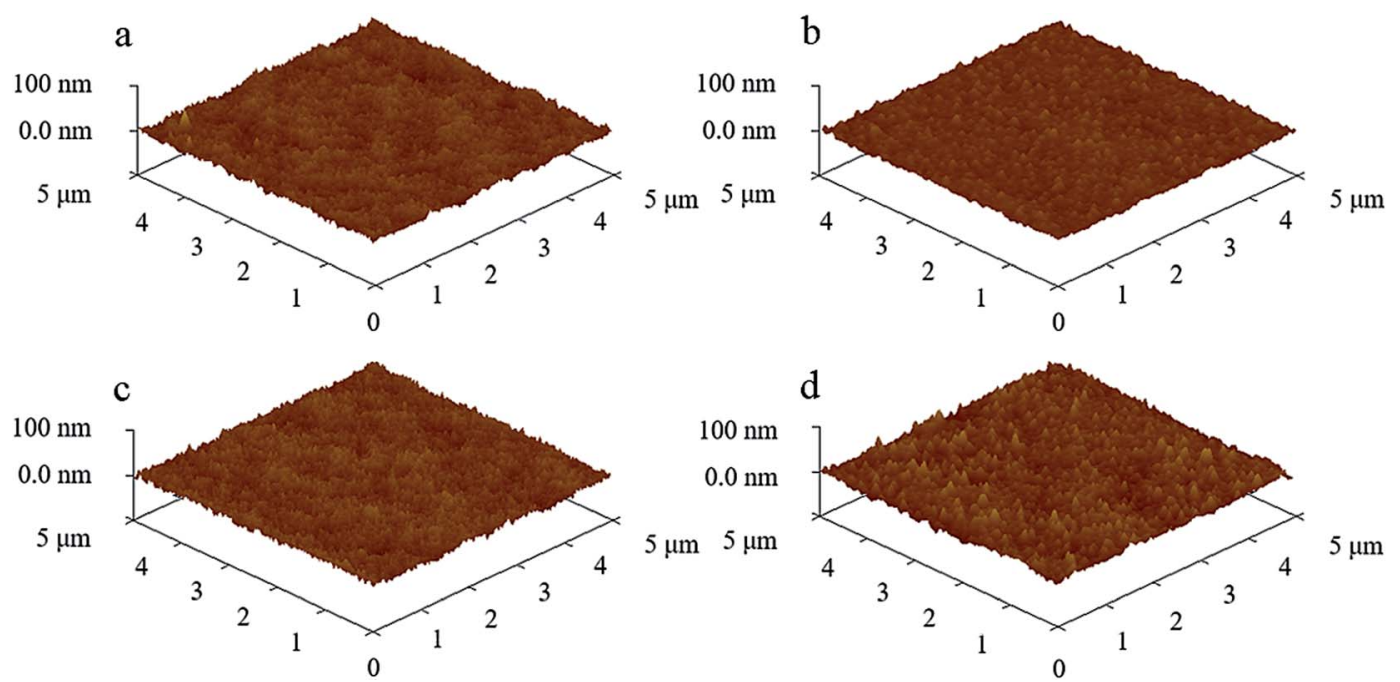

Fig. 3 AFM images of the original membrane (a) and Tween-20 coated membranes under the coating temperature of $40{ }^{\circ} \mathrm{C}(\mathrm{b}), 80{ }^{\circ} \mathrm{C}(\mathrm{c})$ and $120{ }^{\circ} \mathrm{C}(\mathrm{d})$ 
roughness could decrease the accumulation of foulants on the valleys of membrane surface, thus contributing to membrane fouling control..$^{33}$ To this end, taking the energy conversation into consideration, $40{ }^{\circ} \mathrm{C}$ was chosen as the optimized coating temperature in this study.

3.1.2 Coating concentration. The effect of coating concentration (CC) on surface modification is illustrated in Fig. 4. As shown in Fig. 4(a), the contact angles of PVDF microfiltration membranes were all less than $90^{\circ}$ and showed hydrophilic behavior after coated by Tween-20. It was noteworthy that the effect of hydrophilic modification was more obvious with $\mathrm{CC}$ of $4.5 \mathrm{mmol} \mathrm{L}^{-1}$, and the contact angle decreased from $105^{\circ}$ to $70^{\circ}$. The effectiveness of modification was evaluated by the changes of contact angle and transmembrane pressure. Contact angle could reflect the hydrophilic property of modified membranes. ${ }^{29}$ The decrease of contact angle indicated the increase of the hydrophilicity of membrane. ${ }^{34-38}$ As illustrated in Fig. 4(b), the increasing rate of transmembrane pressure even exceeded the original membrane with CC of 1.8 and $18.0 \mathrm{mmol}$ $\mathrm{L}^{-1}$, respectively. With CC of $4.5 \mathrm{mmol} \mathrm{L}^{-1}$, the transmembrane pressure changed from $0.7 \mathrm{kPa}$ to $10.7 \mathrm{kPa}$ with effluent flow rate increased from $2.5 \mathrm{~L} \mathrm{~h}^{-1}$ to $11.5 \mathrm{~L} \mathrm{~h}^{-1}$. By contrast, with the effluent flow rate increased from $2.5 \mathrm{~L} \mathrm{~h}^{-1}$ to $11.5 \mathrm{~L} \mathrm{~h}^{-1}$, the transmembrane pressure changed from $0.9 \mathrm{kPa}$ to $12.4 \mathrm{kPa}$ under $\mathrm{CC}$ of $9.0 \mathrm{mmol} \mathrm{L}^{-1}$. It was noted that the changes of transmembrane pressure reflected membrane flux. Specifically, lower transmembrane pressure of modified membrane than original membrane under the same flow rate indicated excellent
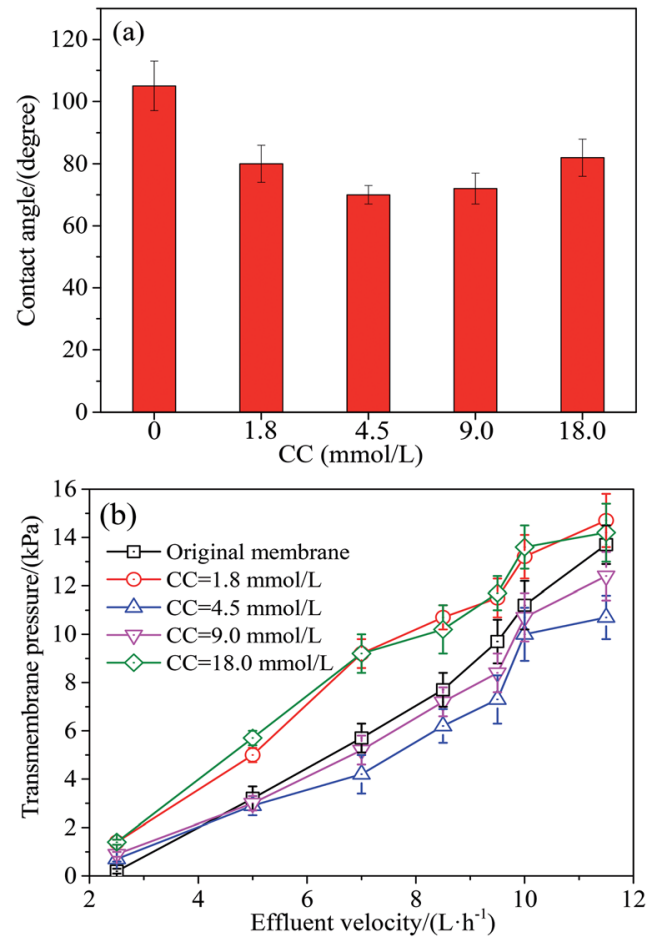

Fig. 4 Effect of coating concentration (CC) of Tween-20 on membrane modification: (a) membrane contact angle, (b) transmembrane pressure. Experimental conditions: $T=40^{\circ} \mathrm{C}$, coating time $=15$ min, drying time $=45 \mathrm{~min}$. modification result. ${ }^{39}$ Considering the influence of Tween-20 concentration on contact angle, $4.5 \mathrm{mmol} \mathrm{L}^{-1}$ was more appropriate for surface modification. The result was similar with the study of Lu et al., ${ }^{40}$ which reported that the higher of Tween- 20 concentration, the faster the flux decreased, and the appropriate CC for surface modification of polysulfone ultrafiltration membrane was $1.0 \mathrm{~g} \mathrm{~L}^{-1}$ (the lowest CC).

3.1.3 Coating time. The influence of coating time on surface modification is shown in Fig. 5. The contact angle changed obviously when the coating time varied from $10 \mathrm{~min}$ to $45 \mathrm{~min}$. With the coating time of $45 \mathrm{~min}$, the hydrophilicity of membrane was significantly improved with the contact angle of $70^{\circ}$. With respect to the transmembrane pressure curve, it seemed that the coating time of 10 min exhibited little influence on the increase of transmembrane pressure, and the curve of modified membrane nearly overlapped with origin membrane. It was speculated that a stable hydration layer could not be formed between non-ionic surfactant and membrane surface in $10 \mathrm{~min}$, resulting in the detachment of non-ionic surfactant with the increase of effluent velocity, and a slightly greater transmembrane pressure than the original membrane. Under the coating times of 15,25 and $45 \mathrm{~min}$, the rising trend of transmembrane pressure for the modified membrane was well controlled, and the best performance was achieved at the longest coating time (45 $\mathrm{min})$. This was likely because the surfactant could be more tightly attached to the membrane surface with the increase of coating time, forming a stable hydration layer. Through comprehensive evaluation of contact angle and transmembrane pressure, $45 \mathrm{~min}$ was more
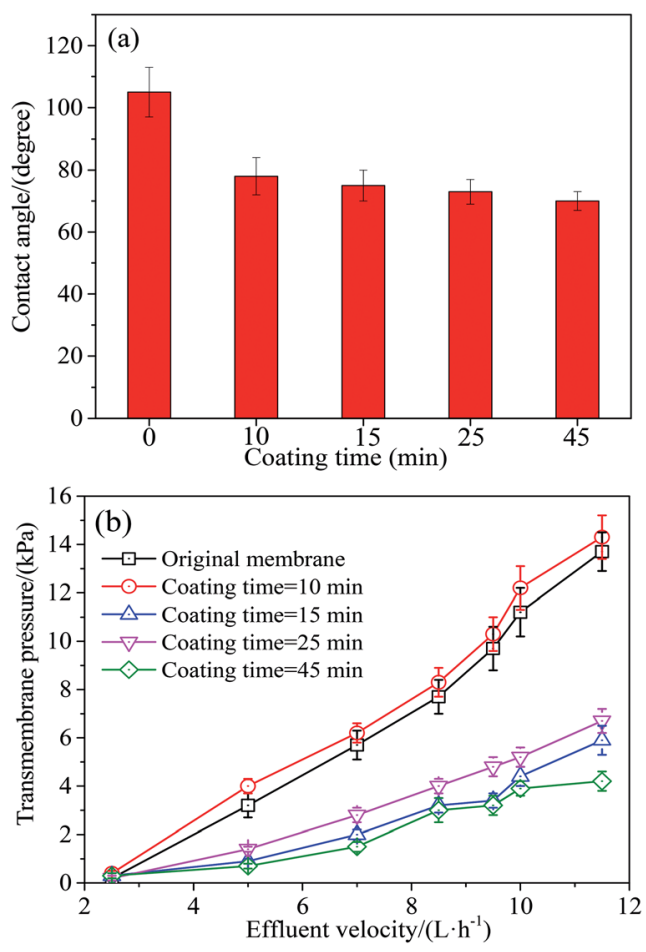

Fig. 5 Effect of coating time on membrane modification: (a) membrane contact angle, (b) transmembrane pressure. Experimental conditions: $T=40^{\circ} \mathrm{C}, \mathrm{CC}=4.5 \mathrm{mmol} \mathrm{L}^{-1}$, drying time $=45 \mathrm{~min}$. 
appropriate for surface coating. Under this condition, a stable water layer was formed. Similarly, Lu et al. ${ }^{40}$ also considered that the appropriate coating time was more than 30 min when using Tween-20 as a surface modification material for polysulfone ultrafiltration membrane, by which a stable hydration layer can be obtained.

3.1.4 Drying time. Drying time is a key factor influencing the attachment of Tween-20 coating on membrane surface. The influence curve of drying time on membrane modification is illustrated in Fig. 6. As seen in Fig. 6(a), the contact angle decreased from $77^{\circ}$ to $70^{\circ}$ with the drying time increased from $30 \mathrm{~min}$ to $45 \mathrm{~min}$. However, when the drying time extended more (i.e., $90 \mathrm{~min}, 120 \mathrm{~min}$ ), the contact angle increased consequently. As shown in Fig. 6(b), compared with the original membrane, the increase rate of transmembrane pressure was significantly decreased under the drying times of $30 \mathrm{~min}$ and $45 \mathrm{~min}$, indicating excellent fouling control performance. However, the drying times of $90 \mathrm{~min}$ and $120 \mathrm{~min}$ even accelerated the increase of transmembrane pressure. When the effluent flow rate increased from $2.5 \mathrm{~L} \mathrm{~h}^{-1}$ to $11.5 \mathrm{~L} \mathrm{~h}^{-1}$, the transmembrane pressure increased from $0.2 \mathrm{kPa}$ to $5.2 \mathrm{kPa}, 3.9$ $\mathrm{kPa}, 14.7 \mathrm{kPa}$, and $17.7 \mathrm{kPa}$ under the drying times of $30 \mathrm{~min}$, $45 \mathrm{~min}, 90 \mathrm{~min}$, and $120 \mathrm{~min}$, respectively. This was because that the process of drying can reinforce the stability between the membrane surface and non-ionic surfactant at certain temperature. The original membrane structure might be destroyed when the drying time exceeded $45 \mathrm{~min}$. An appropriate drying time could significantly increase the hydrophilicity of membrane, thus decreasing the contact angle. While the lowest
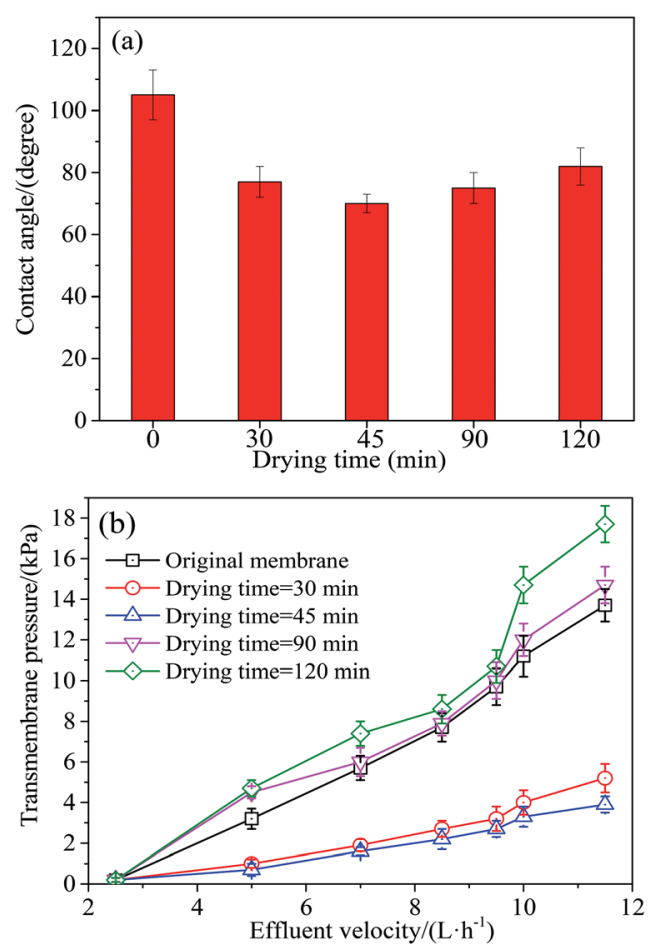

Fig. 6 Effect of drying time on membrane modification: (a) membrane contact angle, (b) transmembrane pressure. Experimental conditions: $T=40^{\circ} \mathrm{C}, \mathrm{CC}=4.5 \mathrm{mmol} \mathrm{L}^{-1}$, coating time $=25 \mathrm{~min}$. contact angle was obtained with the drying time of $45 \mathrm{~min}$, showing the best hydrophilic modification result. Accordingly, 45 min was appropriate and chosen as the optimized drying time in this study.

\subsection{Removal performance of Tween-20 coated PVDF membrane}

The removal performance of COD and SS by original and modified membranes (under the optimized preparation parameters) were comparably investigated during wastewater treatment in MBR, and the results are shown in Fig. 7. It seemed that both original and modified membranes exhibited efficient removal effect for COD and SS at initial period (0-5 d). Then, the rejection efficiency of SS kept stable within the whole operation period (i.e., the average SS rejection rate of the original membrane was $97.38 \%$, while for the modified membrane was $97.53 \%)$. Nevertheless, the rejection rate of COD for original membrane was rapidly decreased after 20 days (i.e., from $92.77 \%$ to $86.28 \%$ ), while modified membrane still showed a stable ability on the removal of COD. Furthermore, the modified membrane can keep in efficient operation (e.g., the average COD rejection rate was $94.56 \%$ ) for about 46 days. Comparably, the original membrane kept stable operation for only about 25 days. The results indicated that hydrophilic modification of membrane surface can effectively improve the removal efficiency and prolong its service life. It was noteworthy that the better COD rejection rate for modified membrane was likely due to the fact that the modified membrane had better
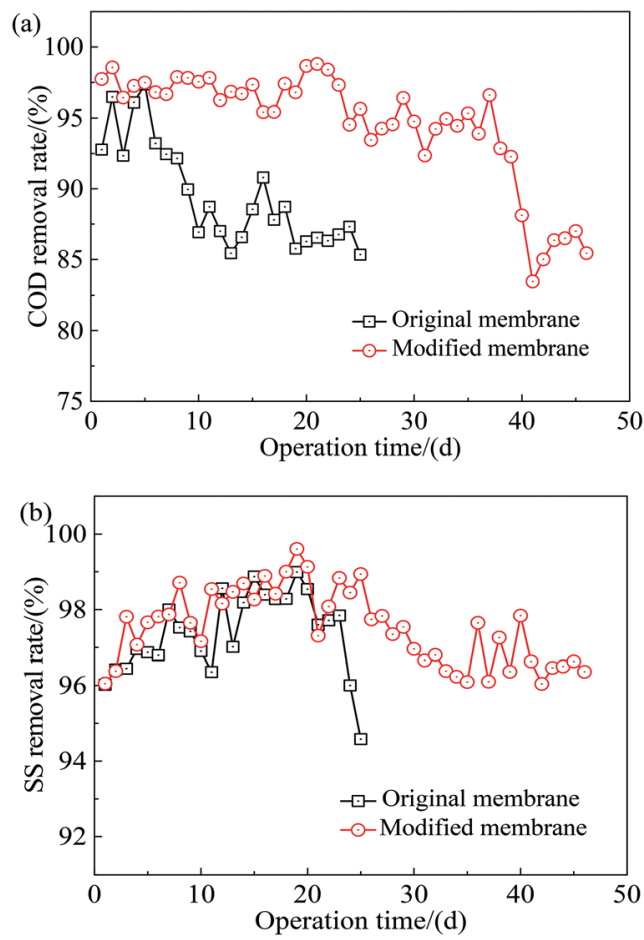

Fig. 7 Rejection efficiency of COD (a) and SS (b) by Tween-20 coated PVDF membrane during wastewater treatment. Experimental conditions: $T=40{ }^{\circ} \mathrm{C}, \mathrm{CC}=4.5 \mathrm{mmol} \mathrm{L}^{-1}$, coating time $=45 \mathrm{~min}$, drying time $=45 \mathrm{~min}$. 
hydration speciality. ${ }^{41}$ The above results demonstrated the feasibility of surface coating with Tween-20 to improve the removal performance of pollutants (i.e., COD and SS) and prolong the operation time during domestic wastewater treatment.

\subsection{Fouling control performance of Tween-20 coated PVDF membrane}

The antifouling performance of Tween-20 coated PVDF membrane in MBR was investigated during wastewater treatment, and the results are shown in Fig. 8. As seen in Fig. 8(a), the transmembrane pressure of the original membrane increased from $1.3 \mathrm{kPa}$ to $4.8 \mathrm{kPa}$ with a growth rate of $233 \%$ during 25 days operation. With respect to the modified membrane, the transmembrane pressure increased from 1.6 $\mathrm{kPa}$ to $5.9 \mathrm{kPa}$ during 46 days operation with a growth rate of $260 \%$. When the growth rate was approximately the same, the MBR with original membrane as the core component only ran for 25 days, while the modified membrane ran for 46 days. Membrane surface modification extended the operation time by 20 days, which was very economical for saving the cleaning cost. It was noted that due to the free surfactant on membrane surface in the initial period, the transmembrane pressure increased in the first 5 days, and then decreased from the 6th day after washing away free surfactant. To this end, from the standpoint of transmembrane pressure, surface coating modification with Tween-20 was effective for membrane fouling control.

During wastewater treatment, membrane fouling of MBR was mainly caused by EPS. ${ }^{42}$ The main components of EPS were proteins and polysaccharides, etc. ${ }^{\mathbf{4 3 , 4 4}}$ The higher the protein contents in EPS, the stronger the hydrophobicity of wastewater. At the same time, the electrical property of proteins affected the surface charge of the flocs, possibly because positively charged and non-polar amino acids were dominant in proteins. ${ }^{45}$ Therefore, the effect of protein on membrane fouling was more direct. It should be noted that proteins are hydrophobic substances, which tend to deposit on membrane surface. Under the action of high-speed shear force on the membrane surface, secondary adsorption was formed on the membrane pore wall, resulting in smaller and blocked membrane pores and chemical pollution. Fig. 8(b) shows the accumulation of proteins on membrane surface. The concentration of proteins accumulated on the original membrane surface increased from $0.20 \mathrm{~g} \mathrm{~m}^{-2}$ to $87.30 \mathrm{~g} \mathrm{~m}^{-2}$ after 25 days operation, while for the modified membrane the concentration was increased to $37.85 \mathrm{~g} \mathrm{~m}^{-2}$ after 46 days operation. It seemed that surface modification dramatically reduced the concentration of proteins accumulated on membrane surface, indicating that hydrophilic modification with Tween-20 was efficient for reducing protein accumulation.

The relationship between protein concentration and transmembrane pressure was also investigated in this study, and the result is illustrated in Fig. 8(c). It seemed that for both original and modified membranes, the transmembrane pressure increased with an exponential function as the increase of
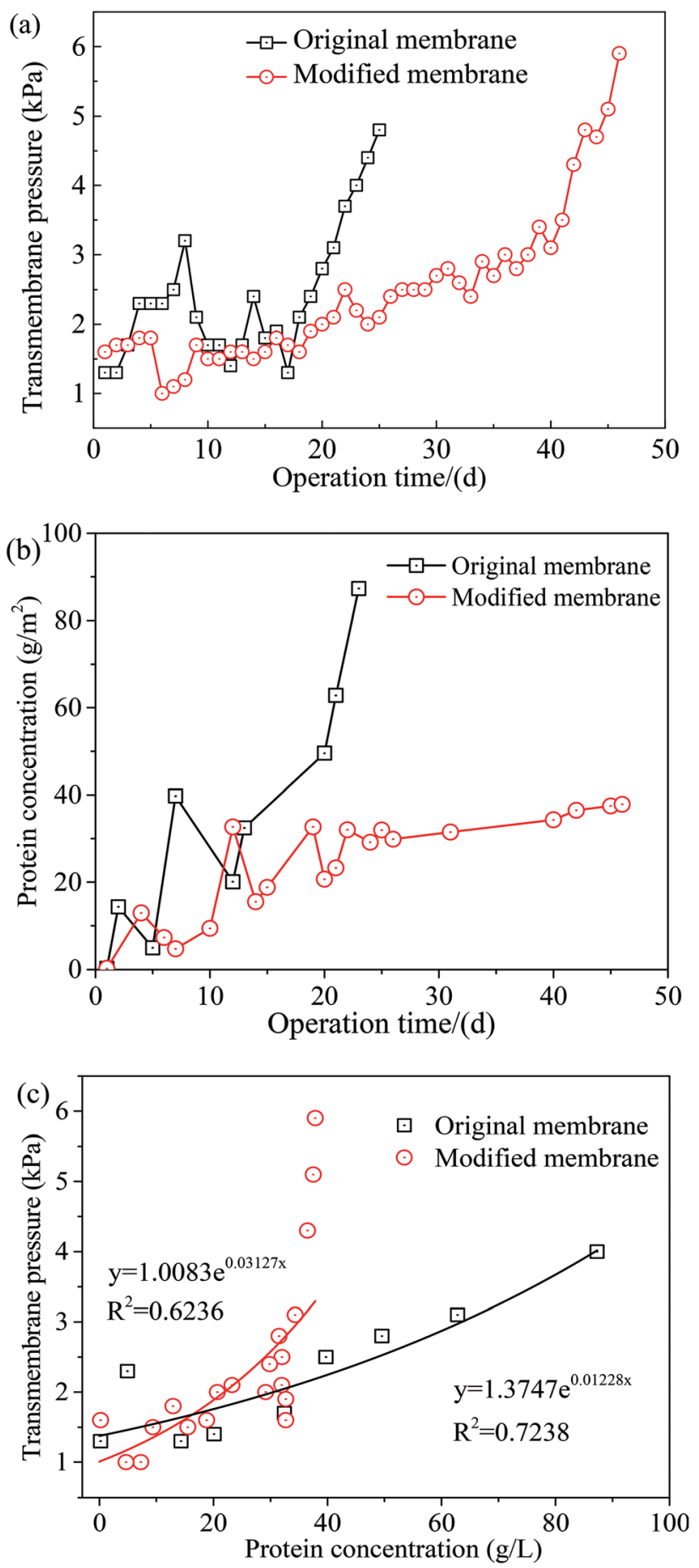

Fig. 8 Membrane fouling control of Tween-20 coated PVDF membrane during wastewater treatment: (a) increase of transmembrane pressure, (b) accumulation of proteins on membrane surface, (c) correlation between protein concentration and transmembrane pressure.

protein concentration $\left(R^{2}=0.7238\right.$ and 0.6236 for original and modified membrane, respectively). The results indicated that both transmembrane pressure and protein concentration could closely reflect the condition of membrane fouling, and hydrophilic modification with Tween-20 has a great potential for mitigating membrane fouling during wastewater treatment. 


\subsection{Stability of Tween-20 coated PVDF membrane}

To verify the stability of Tween-20 modified membrane, an immersion test lasted for 20 days was carried out with ultrapure water, $0.4 \% \mathrm{HCl}$ and $0.4 \% \mathrm{NaOH}$, respectively. The values of contact angle under different immersion conditions were investigated and the results are shown in Fig. 9. It seemed that the contact angle changed little after immersing for 20 days in all the solutions, indicating that Tween-20 was remained on membrane surface without significant loss during immersion test. The experimental result verified the stability of Tween-20 coating to some extent.

As shown in Fig. $\mathrm{S} 3, \dagger$ the spectrum of the virgin membrane presented the typical spectrum of corresponding polymers for PVDF. To be specific, the absorption peak at $1401 \mathrm{~cm}^{-1}$ represents $\mathrm{CH}_{2}$ wagging, while the peak at $1170 \mathrm{~cm}^{-1}$ results from $-\mathrm{CF}_{2}$ stretching. ${ }^{46}$ With respect to the Tween-20 modified PVDF membrane, peaks at 1713 and $1100 \mathrm{~cm}^{-1}$ are attributed to the carbonyl group $(\mathrm{C}=\mathrm{O})$ and $\mathrm{C}-\mathrm{O}-\mathrm{C}$ asymmetric stretching vibration in the ester bond $(\mathrm{O}-\mathrm{C}=\mathrm{O})$ in Tween-20, respectively. ${ }^{47}$ After immersion in $0.4 \% \mathrm{NaOH}$ for 20 days, the spectrum of modified membrane changed little, suggesting that Tween-20 coating layer was still attached on membrane surface. The results of FTIR spectra indicated the stability of Tween-20 modified membrane from the standpoint of surface functional groups. In addition, the excellent stability of Tween20 coating was also reported by Xie et al. ${ }^{48}$ They modified polypropylene microporous membranes by the adsorption of Tween-20, and found that Tween-20 was still remained on membrane surface after running for 12 days in a MBR, followed by physical and chemical cleaning.

Overall, it should be noted that the removal and antifouling performance of Tween-20 coated PVDF membrane were investigated in a lab-scale MBR system, and the obtained results might not be very relevant for full-scale applications due to the smaller scale and short operation time. Further pilot or fullscale studies should be carried out to advocate its practical applications. In addition, the durability of Tween-20 coated PVDF membrane still needs to be further verified during longterm full-scale operation.

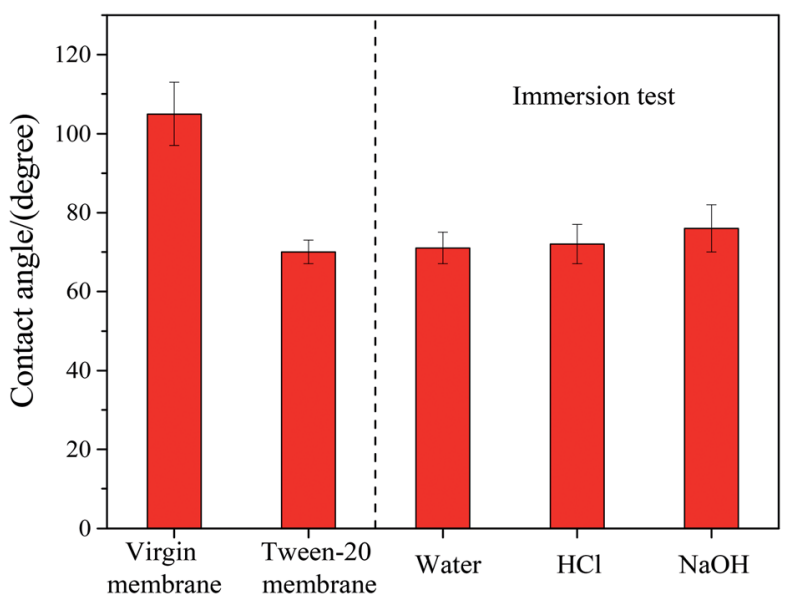

Fig. 9 Effect of immersion with ultrapure water, $\mathrm{HCl}$ and $\mathrm{NaOH}$ on the contact angle of Tween-20 coated membrane.

\section{Conclusion}

In this study, Tween-20 coated PVDF membranes were prepared and the optimized preparation parameters (i.e., coating temperature, coating concentration, coating time and drying time) were investigated. The removal and membrane fouling control performance were further evaluated, and the following conclusions can be drawn:

(1) The optimized preparation parameters for Tween-20 coated PVDF microfiltration membrane are as follows: coating temperature of $40{ }^{\circ} \mathrm{C}$, coating concentration of $4.5 \mathrm{mmol} \mathrm{L}^{-1}$, coating time of $45 \mathrm{~min}$, and drying time of $45 \mathrm{~min}$.

(2) The contact angle of PVDF microfiltration membrane decreased from $105^{\circ}$ to $70^{\circ}$ under the best modification conditions, indicating an efficient hydrophilic modification effect.

(3) The coating modification of PVDF microfiltration membrane is simple and practical, which effectively improved pollutants removal in MBR during domestic wastewater treatment with rejection efficiencies of $94.56 \%$ and $97.53 \%$ for COD and SS, respectively.

(4) Surface coating modification with Tween-20 mitigated the increase of transmembrane pressure and reduced the concentration of proteins accumulated on membrane surface, which was effective for membrane fouling control and extending the operation time of MBR from 25 to 46 days.

(5) Tween-20 coating was stable and remained on membrane surface without significant loss after immersion in $0.4 \% \mathrm{NaOH}$ for 20 days.

\section{Conflicts of interest}

There are no conflicts to declare.

\section{Acknowledgements}

This work was supported by the National Key Technology Support Program (2017YFF0209903), the China Postdoctoral Science Foundation (2019M652427), the Natural Science Foundation of Shandong Province (ZR2019BEE058, ZR2018BEE036), Science and Technology Plan of Shandong Province Education Department (J18KA202), and the Doctoral Research Fund of Shandong Jianzhu University (XNBS1806, XNBS1822).

\section{References}

1 H. Zhao, J. Cui, S. Wang and S. Lindley, J. Environ. Manage,, 2018, 213, 247.

2 M. Z. Bieroza, A. L. Heathwaite, M. Bechmann, K. Kyllmar and P. Jordan, Sci. Total Environ., 2018, 630, 738.

3 O. Kiguchi, G. Sato and T. Kobayashi, Environ. Sci. Pollut. Res., 2016, 23, 1-17.

4 M. Molinos-Senante, S. Porcher and A. Maziotis, Environ. Sci. Pollut. Res., 2017, 24, 16994-17005.

5 Y. Liu, P. Wu, F. Liu, F. Li, X. An, J. Liu, Z. Wang, C. Shen and W. Sand, Environ. Sci. Technol., 2019, 53, 1527-1535. 
6 Q. Li, Q. Y. Bi, H. H. Lin, L. X. Bian and X. L. Wang, J. Membr. Sci., 2013, 427, 155-167.

7 W. Guo, H. H. Ngo and J. Li, Bioresour. Technol., 2012, 122, 27-34.

8 D. Liu, Z. Jing, Q. Ming and C. He, Sep. Purif. Technol., 2016, 171, 1-10.

9 X. Cheng, P. Li, W. Zhou, D. Wu, C. Luo, W. Liu, Z. Ren and H. Liang, Chemosphere, 2019, 221, 812-823.

10 X. Cheng, D. Wu, H. Liang, X. Zhu, X. Tang, Z. Gan, J. Xing, X. Luo and G. Li, Water Res., 2018, 145, 39-49.

11 C. Ma, Y. Liu, F. Li, C. Shen, M. Huang, Z. Wang, C. Cao, Q. Zhou, Y. Sheng and W. Sand, Sep. Purif. Technol., 2019, 209, 707-713.

12 H. Xu, B. Yang, Y. Liu, F. Li, C. Shen, C. Ma, Q. Tian, X. Song and W. Sand, World J. Microbiol. Biotechnol., 2018, 34, 165.

13 J. Xu, W. Zhi, J. Wang and S. Wang, Desalination, 2015, 365, 398-406.

14 H. Lin, M. Zhang, F. Wang, F. Meng, B. Q. Liao, H. Hong and J. Che, J. Membr. Sci., 2014, 460, 110-125.

15 Y. Xie, R. Tayouo and S. P. Nunes, J. Appl. Polym. Sci., 2015, 132, 41549.

16 J. Scheirs, Modern fluoropolymers: high performance polymers for diverse applications, Wiley, 1997.

17 A. Rahimpour, M. Jahanshahi, B. Rajaeian and M. Rahimnejad, Desalination, 2011, 278, 343-353.

18 Y. Zhang, Z. Jing, H. Chu, X. Zhou and W. Yong, Desalination, 2014, 344, 71-78.

19 C. Sun and X. Feng, Sep. Purif. Technol., 2017, 185, 94-102.

20 X. Zhao, C. Jing, S. Chen, J. Zhang and X. Wang, Colloid Polym. Sci., 2010, 288, 1327-1332.

21 L. Bai, F. Qu, H. Liang, J. Ma, H. Chang, M. Wang and G. Li, Desalination, 2013, 319, 18-24.

22 S. Boributh, A. Chanachai and R. Jiraratananon, J. Membr. Sci., 2009, 342, 97-104.

23 S. Zhang, L. Wu, F. Deng, D. Zhao, C. Zhang and C. Zhang, RSC Adv., 2016, 6, 71287-71294.

24 H. Shi, H. Yi, P. Yang, H. Di, G. Zeng, Z. Lei and C. Zhang, J. Membr. Sci., 2016, 506, 60-70.

25 F. Liu, B. K. Zhu and Y. Y. Xu, Appl. Surf. Sci., 2006, 253, 2096-2101.

26 H.-H. Chang, S.-C. Chen, D.-J. Lin and L.-P. Cheng, J. Membr. Sci., 2014, 466, 302-312.

27 S.-C. Chen, H.-H. Chang, T.-W. Cheng, Y.-L. Su and L.-P. Cheng, J. Appl. Polym. Sci., 2017, 134, 44600.
28 Y.-j. Xie, H.-y. Yu and Z.-k. Xu, Chin. J. Polym. Sci., 2006, 24, 421-429.

29 Q. Li, X. Pan, Z. Qu, X. Zhao, Y. Jin, H. Dai, B. Yang and X. Wang, Desalination, 2013, 309, 38-45.

30 S. S. Adav and D.-J. Lee, J. Hazard. Mater., 2008, 154, 11201126.

31 O. H. Lowry, N. J. Rosebrough, A. L. Farr and R. J. Randall, J. Biol. Chem., 1951, 193, 265-275.

32 American Public Health Association, Standard methods for the examination of water and wastewater, 1998.

33 X. Cheng, H. Liang, F. Qu, A. Ding, H. Chang, B. Liu, X. Tang, D. Wu and G. Li, Chem. Eng. J., 2017, 308, 1010-1020.

34 N. Uzal, N. Ates, S. Saki, Y. E. Bulbul and Y. Chen, Sep. Purif. Technol., 2017, 187, 118-126.

35 J. Lu, Z. Tang, K. J. Park-Lee, D. W. Hess and V. Breedveld, Sep. Purif. Technol., 2017, 184, 394-403.

36 S. Yu, X. Zhang, F. Li and X. Zhao, Sep. Purif. Technol., 2018, 194, 404-409.

37 J. Garcia-Ivars, M.-I. Alcaina-Miranda, M.-I. Iborra-Clar, J.-A. Mendoza-Roca and L. Pastor-Alcañiz, Sep. Purif. Technol., 2014, 128, 45-57.

38 B. S. Mbuli, E. N. Nxumalo, W. K. Rui, V. L. Pillay, Y. Oren, C. Linder and B. B. Mamba, Sep. Purif. Technol., 2013, 120, 328-340.

39 K. Li, H. Liang, F. Qu, S. Shao, H. Yu, Z.-s. Han, X. Du and G. Li, J. Membr. Sci., 2014, 471, 94-102.

40 X. Lu, S. Chen, C. Li and B. Wang, Membr. Sci. Technol., 1997, 17, 36-41.

41 Q. Feng, J. Bao, X. Xie and C. Lu, Environ. Pollut. Control, 2016, 38, 67-71.

42 M. Zhuo, O. K. Abass and K. Zhang, RSC Adv., 2018, 8, 1279912807.

43 W. Yu, N. J. Graham and G. D. Fowler, Water Res., 2016, 95, 1-10.

44 A. Ding, J. Wang, D. Lin, X. Tang, X. Cheng, G. Li, N. Ren and H. Liang, Water Res., 2017, 126, 197-207.

45 W. Lee, S. Kang and H. Shin, J. Membr. Sci., 2003, 216, 217227.

46 V. Puspitasari, A. Granville, P. Le-Clech and V. Chen, Sep. Purif. Technol., 2010, 72, 301-308.

47 A. C. Borges, A. Jayakrishnan, P.-E. Bourban, C. J. G. Plummer, D. P. Pioletti and J.-A. E. Månson, Mater. Sci. Eng., C, 2012, 32, 2235-2241.

48 Y.-j. Xie, H.-y. Yu, S.-y. Wang and Z.-k. Xu, J. Environ. Sci., 2007, 19, 1461-1465. 